Original Article

\title{
The beneficial effect of glycerophosphocholine to local fat accumulation: a comparative study with phosphatidylcholine and aminophylline
}

\author{
Go Woon Kim and Sung Hyun Chung* \\ Department of Pharmacology, College of Pharmacy, Kyung Hee University, Seoul 02447, Korea
}

\section{ARTICLE INFO}

Received December 11, 2020

Revised April 27, 2021

Accepted May 6, 2021

*Correspondence

Sung Hyun Chung

E-mail: suchung@khu.ac.kr

Key Words

Aminophylline

Choline alfoscerate

Glycerophosphocholine

Lipolysis

Mesotherapy

Phosphatidylcholine

\begin{abstract}
Injection lipolysis or mesotherapy gained popularity for local fat dissolve as an alternative to surgical liposuction. Phosphatidylcholine (PPC) and aminophylline (AMPL) are commonly used compounds for mesotherapy, but their efficacy and safety as lipolytic agents have been controversial. Glycerophosphocholine (GPC) is a choline precursor structurally similar to PPC, and thus introduced in aesthetics as an alternative for PPC. This study aimed to evaluate the effects of GPC on adipocytes differentiation and lipolysis and compared those effects with PPC and AMPL using in vitro and in vivo models. Adipogenesis in 3T3-L1 was measured by Oil Red O staining. Lipolysis was assessed by measuring the amount of glycerol released in the culture media. To evaluate the lipolytic activity of GPC on a physiological condition, GPC was subcutaneously injected to one side of inguinal fat pads for 3 days. Lipolytic activity of GPC was assessed by hematoxylin and eosin staining in adipose tissue. GPC significantly suppressed adipocyte differentiation of 3T3-L1 in a concentration-dependent manner (22.3\% inhibition at $4 \mathrm{mM}$ of GPC compared to control). Moreover, when lipolysis was assessed by glycerol release in 3T3-L1 adipocytes, 6 mM of GPC stimulated glycerol release by two-fold over control. Subcutaneous injection of GPC into the inguinal fat pad of mice significantly reduced the mass of fat pad and the size of adipocytes of injected site, and these effects of GPC were more prominent over PPC and AMPL. Taken together, these results suggest that GPC is the potential therapeutic agent as a local fat reducer.
\end{abstract}

\section{INTRODUCTION}

Obesity is a serious medical condition characterized by excessive body fat accumulation which results in significant metabolic complications [1]. The accumulation of body fat greatly affects one's physical appearance ending up with disfigurement, and obese patients often suffer from negative social consequences [2]. The fat reduction in a certain area is hard to be achieved by general weight loss methods such as exercise and diet. Targeted fat reduction procedures for body and face contouring have gained remarkable global interest, and various noninvasive procedures have been developed worldwide [3]. Injection lipolysis, based on mesotherapy, is one of the easily accepted noninvasive treatment by patients. This procedure is performed by subcutaneous injection of lipolytic substances to induce local fat reduction [4], and several injection formulations have been introduced and utilized in injection lipolysis. Most of the lipid reducing agents used in injection lipolysis formulations are used off-label, and thus their efficacy and safety for the removal of local fat is controversial.

Glycerophosphocholine (GPC), also known as choline alfoscerate, was originally approved for treatment of mental integrity in patients with dementia. GPC shares structural similarity with one

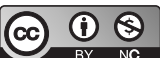

This is an Open Access article distributed under the terms of the Creative Commons Attribution Non-Commercial License, which permits unrestricted non-commercial use, distribution, and reproduction in any medium, provided the original work is properly cited. Copyright @ Korean J Physiol Pharmacol, pISSN 1226-4512, elSSN 2093-3827
Author contributions: G.W.K. designed and performed the experiments, interpreted the data, and wrote the manuscript. S.H.C. directed the experiment and data interpretation, and thoroughly revised the manuscript. Both authors read and approved the final manuscript. 
of the most widely used ingredient called phosphatidylcholine (PPC) by having choline moiety, and thus GPC was introduced in clinical practice as an alternative lipolytic agent for PPC. GPC is a natural source of choline and the use of GPC as an alternative to enhance lipolysis is based on the hypothesis that GPC would stimulate lipid metabolism as choline plays important role in the lipid metabolism [5]. Despite some anecdotal evidence, the efficacy of GPC onto local fat reduction has not been thoroughly evaluated. Therefore, here we evaluated the lipolytic potential of GPC and compared the effects with two off-label agents for injection lipolysis, PPC and aminophylline (AMPL), using in vitro and in vivo models of obesity.

\section{METHODS}

\section{Materials}

Cell culture reagents including Dulbecco's modified Eagle medium (DMEM), penicillin-streptomycin antibiotics, and fetal bovine serum (FBS) were purchased from Gibco (Grand Island, NY, USA). The experimental solutions used in this study; Alfocholine, Lipobean, and Aminophylline, were provided from Beauvous Co. (Seoul, Korea), and the active component of each solution is described in Table 1. All other reagents were from Sigma (St. Louis, MO, USA) unless otherwise stated.

\section{Cell culture and cell viability assay}

Mouse embryonic fibroblast 3T3-L1 cells were purchased from the American Type Culture Collection (Manassas, VA, USA). 3T3-L1 cells were cultured in DMEM containing 10\% bovine serum and 100 units $/ \mathrm{ml}$ penicillin-streptomycin at $37^{\circ} \mathrm{C}$ in an atmosphere of $5 \% \mathrm{CO}_{2}$. The cytotoxicity of compounds was determined by using tetrazolium compound (MTS)-based CellTiter $96 \mathrm{AQ}_{\text {uenous }}$ One solution Cell Proliferation Assay Kit (Promega, Madison, WI, USA) following the manufacturer's protocol. Briefly, 3T3-L1 cells were seeded at $5 \times 10^{3}$ cells/well in a 96-well plate and incubated with compounds. The experimental concentration of each compound was calculated solely using the content of active component (AMPL, PPC, or GPC) in the stock solution shown in Table 1 . After $96 \mathrm{~h}, 20 \mu \mathrm{l}$ of assay solution was added to each well and incubated at $37^{\circ} \mathrm{C}$ for $1 \mathrm{~h}$. The absorbance was then recorded at $490 \mathrm{~nm}$ using a microplate reader (ThermoLabSys- tems, Helsinki, Finland).

\section{Adipocyte differentiation and Oil Red 0 staining}

To induce adipocyte differentiation, 3T3-L1 pre-adipocytes were seeded at $3 \times 10^{5}$ cells/well in a six-well plate. Cells were cultured in differentiation medium (DMEM containing 5\% FBS and $1 \%$ antibiotics) which was refreshed every other day during differentiation. Two days after confluence (designated day 0 ), cells were placed in differentiation medium and were induced to differentiate by hormonal cocktail ( $0.5 \mathrm{mM} \mathrm{IBMX}, 1 \mu \mathrm{M}$ dexamethasone, and $10 \mu \mathrm{g} / \mathrm{ml}$ insulin; MDI) for 4 days. After MDI induction, cells were switched to differentiation medium supplemented with 10 $\mu \mathrm{g} / \mathrm{ml}$ insulin until day 6 , and then maintained in differentiation medium for an additional 2 days. During differentiation, 3T3L1 cells were treated with the compounds as indicated in the figures from day 0 to day 4 . Once the differentiation is complete, cells were washed twice with phosphate buffered saline (PBS), and fixed with $10 \%$ neutral buffered formalin (NBF) for $1 \mathrm{~h}$, then stained with Oil Red $\mathrm{O}$ solution for $1 \mathrm{~h}$ at room temperature. Cells were photographed using a phase-contrast microscope (CKX41; Olympus, Tokyo, Japan) equipped with Olympus DP22 digital camera (Olympus). The Oil Red O dye in adipocytes was eluted with isopropyl alcohol and the absorbance was measured at $540 \mathrm{~nm}$ to quantify stained lipid droplets.

\section{Lipolysis assay}

Two days after the completion of differentiation, 3T3-L1 adipocytes were washed twice with PBS and incubated with the compounds in low glucose $(1 \mathrm{~g} / \mathrm{L})$, serum-free and phenol redfree DMEM supplemented with $2 \%$ fatty acid free BSA. After a 3 $\mathrm{h}$ treatment period, supernatants were collected and analyzed for glycerol content using lipolysis colorimetric assay kit (Sigma) following the manufacturer's indications.

\section{Animals}

All animal experimentation was approved and conducted in accordance with the guidelines from IACUC of Kyung Hee University (approval number KHUASP(SE)17-164). C57BL/6J mice (5 weeks-old, male) were purchased from Daehan Biolink Co. Ltd. (Eumsung, Korea). The mice were randomized and housed in a room under constant temperature $\left(22 \pm 2^{\circ} \mathrm{C}\right)$ and humidity $(50 \pm$

Table 1. Active components of chemical solutions used in the experiment

\begin{tabular}{|c|c|c|c|c|c|}
\hline Label & Product name & Vial volume & Active components & Mass & Company \\
\hline GPC & Alfocholine Inj. & $4 \mathrm{ml}$ & Choline Alfoscerate & $1,000 \mathrm{mg}$ & Daewon Pharmaceutical Co. Ltd. \\
\hline PPC & Lipobean i.v. & $5 \mathrm{ml}$ & Phosphatidylcholine & $250 \mathrm{mg}$ & Jinyang Pharm Co. Ltd. \\
\hline AMPL & Aminophylline Injection Huons & $10 \mathrm{ml}$ & Aminophylline & $250 \mathrm{mg}$ & Huons Co. Ltd. \\
\hline
\end{tabular}

GPC, glycerophosphocholine; PPC, phosphatidylcholine; AMPL, aminophylline. 
5\%) conditions with 12:12 h light-dark cycle. Food and water were supplied ad libitum. After a week of acclimatization to the environment, mice were given a high fat diet (HFD; 60\% fat, \#D12762; Research Diets, New Brunswick, NJ, USA) to induce obesity. After 20-weeks on the HFD, the established diet-induced obesity (DIO) mouse models were used for the experiment.

\section{Injection}

DIO mice were randomly divided into four experimental groups: vehicle ( $10 \mathrm{ml} / \mathrm{kg}$ of normal saline, $\mathrm{n}=8)$, GPC $(1,000$ $\mathrm{mg} / \mathrm{kg}, \mathrm{n}=8)$, PPC (40 mg/kg, $\mathrm{n}=8)$ or AMPL $(40 \mathrm{mg} / \mathrm{kg}, \mathrm{n}=$ 8). Mice were given the corresponding treatments by subcutaneous injection onto right inguinal fat pads between $11 \mathrm{AM}$ to 12 PM for three consecutive days by one skilled experimenter. The administered doses for PPC and AMPL were the animal equivalent dose converted from the doses applied to human in the clinic using dose conversion formula [6]. Typical injection protocol for PPC and AMPL is using a single vial solution consist of $250 \mathrm{mg}$ of either PPC or AMPL [7]. For GPC, the most effective non-toxic dose was determined by preliminary experiments. The left inguinal fat pads were injected with equal volume of saline as a negative control. Body weight and food intake were recorded every day during treatment period. Mice were sacrificed $24 \mathrm{~h}$ after the last injection.

\section{Tissue preparation and histological analysis}

One day after the last injection (on day 4), the mice were euthanized, and inguinal fat pads were removed from both sides and weighed in a blind fashion. Inguinal lymph nodes were carefully removed from the adipose tissue before weighing. The tissues were washed with saline and fixed in $10 \% \mathrm{NBF}$ for $24 \mathrm{~h}$. Then the tissues were embedded in paraffin wax and sectioned at $5 \mu \mathrm{m}$ using microtome. Paraffin-sectioned adipose tissues were stained with hematoxylin and eosin (H\&E). For image analysis, 3 randomly selected fields per mouse for each treatment group were examined under light microscope (BX51, Olympus) at a final magnification of $\times 200$ and photographed with Olympus DP22 digital camera (Olympus). The size of adipocytes was calculated by using Adiposoft as described previously [8].

\section{Statistical analysis}

All values are expressed as mean \pm standard error of the mean (SEM). The experiments were statistically analyzed and compared by using one-way ANOVA followed by Dunnett's post-test in GraphPad Prism 5.0 (La Jolla, CA, USA). p values $<0.05$ were considered statistically significant.

\section{RESULTS}

\section{Cytotoxicity of GPC on 3T3-L1 cells}

To determine non-toxic experimental concentration of GPC in 3T3-L1 cells, we performed MTS-based cell viability assay in 3T3L1 cells that are treated with varying concentrations of GPC for $96 \mathrm{~h}$. As shown in Fig. 1A, GPC had no significant cytotoxicity on 3T3-L1 cells up to $8 \mathrm{mM}$. However, slight morphological change was observed at $8 \mathrm{mM}$ of GPC, and therefore $6 \mathrm{mM}$ of GPC was applied as a maximum concentration in the following study with 3T3-L1 cells. Both PPC and AMPL maintained normal cell viability up to $100 \mu \mathrm{M}$, and thus $100 \mu \mathrm{M}$ was set as a maximum concentration of PPC and AMPL for the subsequent experiments (Fig. 1B, C).

\section{GPC suppresses adipogenesis and lipid accumulation in 3T3-L1 adipocytes}

To examine the effect of GPC on adipogenesis and lipid accumulation, 3T3-L1 preadipocytes were treated with the indicated concentrations of GPC for 4 days during the course of differentiation. On the completion of adipocyte differentiation, the degree of lipid accumulation was assessed by Oil Red O. Treatment with GPC significantly reduced the numbers of lipid droplet and the lipid contents in the adipocytes in a concentration-dependent manner (Fig. 2A, B). Lipid contents were decreased by $22.3 \%$ in the differentiated adipocytes treated with $4 \mathrm{mM} \mathrm{GPC}$ when compare to non-treated control (Fig. 2B). Similarly, $100 \mu \mathrm{M}$ of PPC markedly reduced lipid contents in 3T3-L1 adipocytes during differentiation by $42.4 \%$ compared to that of non-treated control, and no significant differences in lipid contents were observed in AMPL-treated cells with three different concentrations.

\section{GPC enhances basal lipolysis in 3T3-L1 adipocytes}

Next, to determine whether GPC exerts any positive effect on lipolysis, we evaluated basal lipolysis by measuring glycerol release from matured 3T3-L1 adipocytes incubated with GPC. As shown in Fig. 2C, GPC significantly enhanced basal lipolysis in a concentration-dependent manner (2 mM; 1.14-fold, 4 mM; 1.8fold, and $6 \mathrm{mM} ; 2.0$-fold vs. non-treated control), to the similar degree with isoproterenol-induced glycerol release (2.1-fold vs. non-treated control) in which isoproterenol was used as a positive control in this experiment. AMPL also increased glycerol content in media by 1.2 -fold, but no significant release of glycerol was detected in adipocytes treated with PPC (Fig. 2C).

\section{GPC reduces body weight and food intake in DIO mice}

In order to investigate potential effect of GPC in fat reducing, 
A

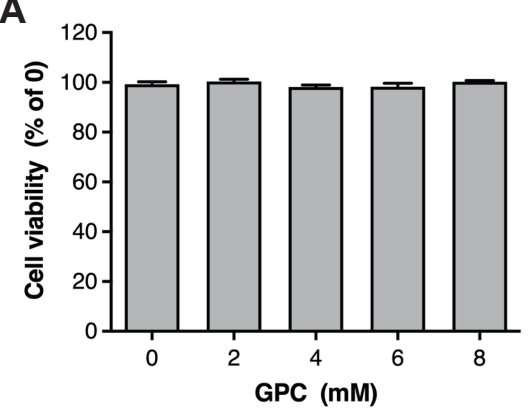

D<smiles>CC(O)COP(=O)([O-])OCC[N+](C)(C)C</smiles>

GPC

\section{C}

B

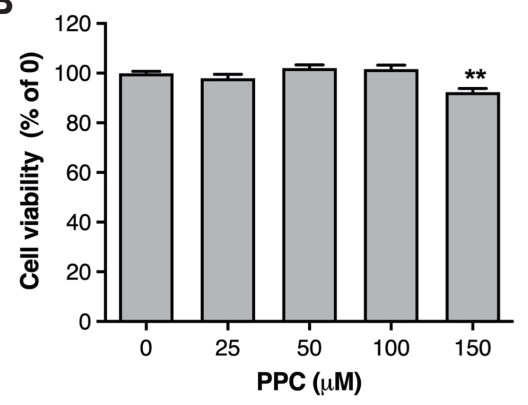

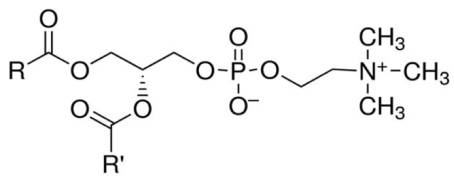

$R, R^{\prime}=$ fatty acid residues
C

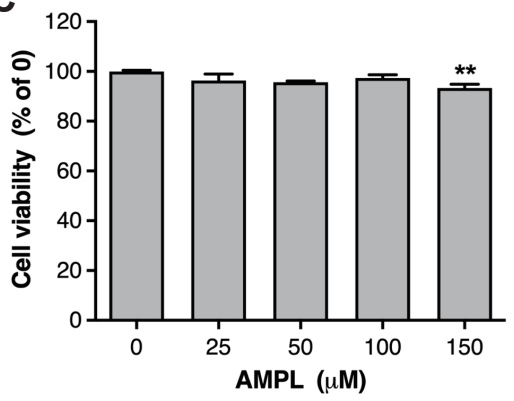

PPC

AMPL

Fig. 1. Effect of GPC on 3T3-L1 adipocyte viability. 3T3-L1 adipocytes were incubated with (A) GPC, (B) PPC and (C) AMPL at indicated concentrations for $96 \mathrm{~h}$. Cell viability was determined by MTS incorporation-based cell proliferation assay. Assays were performed in triplicate for each treatment. (D) Chemical structure of experimental compounds is shown. GPC, glycerophosphocholine; PPC, phosphatidylcholine; AMPL, aminophylline. ${ }^{* *} \mathrm{p}<0.01$ vs. control.
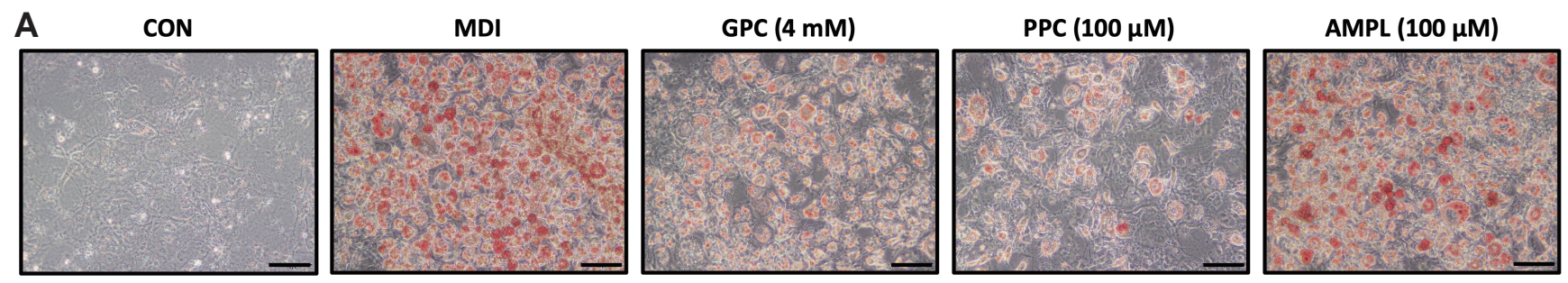

B

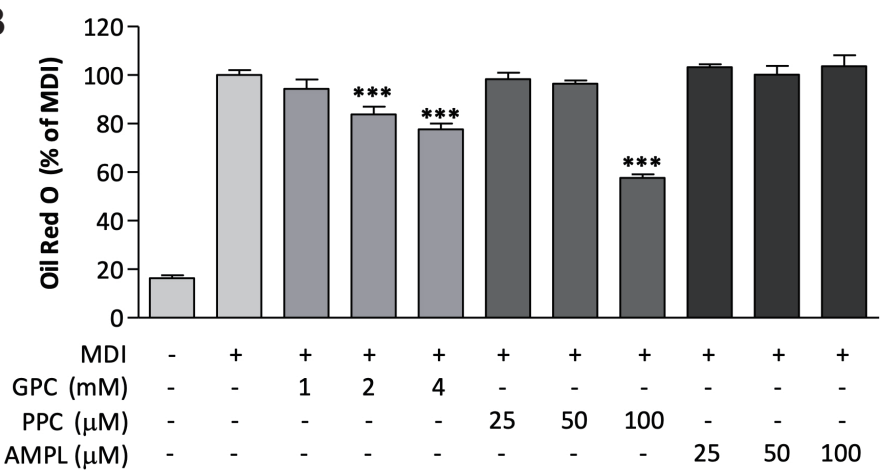

C

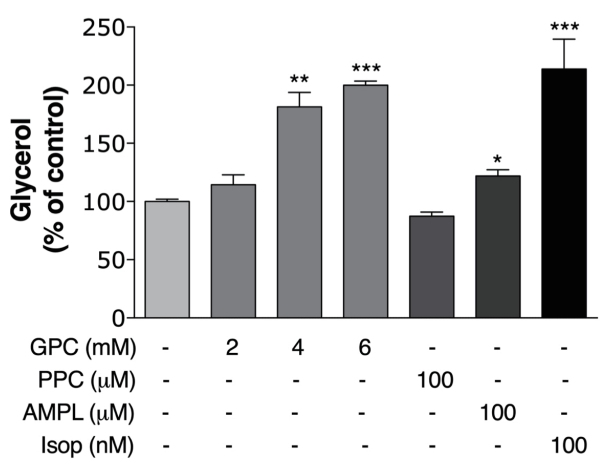

Fig. 2. Effect of GPC on lipid accumulation and lipolysis in 3T3-L1 adipocytes. (A) Representative photomicrographs show lipid accumulation in the cell treated with GPC. 3T3-L1 cells were induced to differentiate with adipogenic cocktail containing IBMX, dexamethasone and insulin (MDI) in the presence or absence of GPC, PPC or AMPL. Lipid accumulation was visualized with Oil Red O staining. Scale $=100 \mu \mathrm{m}$ (B) Intracellular lipid content in differentiated adipocytes concomitantly treated with different compounds was quantified by elution of Oil Red O stain. ${ }^{* * *} \mathrm{p}<0.001$ vs. MDI. (C) Differentiated 3T3-L1 adipocytes were incubated for $3 \mathrm{~h}$ in the absence of presence of GPC, PPC or AMPL. Lipolysis was quantified by glycerol release in incubation medium. Isoproterenol (Isop) was used as a positive control. ${ }^{*} p<0.05,{ }^{* *} p<0.01,{ }^{* * *} p<0.001$ vs. non-treated cells. GPC, glycerophosphocholine; PPC, phosphatidylcholine; AMPL, aminophylline. 
GPC was injected to DIO mice for three consecutive days. When the changes in body weight was monitored during the injection period, no significant changes were observed between GPC and saline control groups (Fig. 3A). Total weight losses during 3 days of injection period in saline-, GPC-, PPC- or AMPL-treated groups were $0.14 \pm 0.24 \mathrm{~g}, 1.04 \pm 0.25 \mathrm{~g}, 0.31 \pm 0.10 \mathrm{~g}$ and $2.02 \pm$ $0.17 \mathrm{~g}$, respectively (Fig. 3B). Interestingly, AMPL-injected mice showed a significant decrease in food intake from day 2 of injection compared to saline-injected mice (Fig. 3C). Total food intake during the injection period was decreased in all experimental groups by $9.17 \%, 11.0 \%$ and $30.5 \%$ in GPC, PPC and AMPL groups, respectively, although the decreases in food intake by GPC and PPC were not statistically significant (Fig. 3D).

\section{GPC reduces inguinal fat mass and adipocyte size}

Inguinal fat mass of injected side was significantly decreased by $11.5 \%$ in GPC-injected mice when compared to the salineinjected mice (Fig. 4A). Reduction in inguinal fat weight was also observed in AMPL-injected mice by $8.9 \%$ although the difference was not statistically significant. The fat loss ratio was calculated by injected tissue mass divided by non-injected tissue mass. The calculated ratios for saline, GPC, PPC and AMPL groups were 1.01 $\pm 0.01,0.96 \pm 0.02,1.01 \pm 0.01$ and $0.98 \pm 0.01$, respectively (Fig. $4 \mathrm{~B})$. Only the difference between saline- and GPC-injected mice showed statistical significance at $\mathrm{p}<0.01$, suggesting that GPC reduced fat accumulation in the injected area. Next, histological analysis was performed using adipose tissue sections prepared from the injection site to compare morphological changes of inguinal adipose tissue between experimental groups. GPC- and
AMPL-injected mice exhibited reduced adipocytes size compared to the saline-injected mice while PPC-injected mice show marked adipocyte destruction (Fig. 4C). The result of histological analysis was also confirmed by distribution of cell population which demonstrates the adipocytes of GPC-injected mice were distributed over smaller size ranges compared to saline-injected mice (Fig. 4D). In addition, mean sizes of GPC, PPC and AMPL-treated adipocytes were $17.9 \%, 10.7 \%$ and $18.7 \%$ smaller than those of salineinjected mice (data not shown).

\section{DISCUSSION}

Mesotherapy and injection lipolysis have gained popularity for reduction of local fat and the appearance of cellulite. The use of lipolytic solutions in injection lipolysis is primarily based on anecdotal evidence and empirical observations in clinics. Here, we evaluated the potential efficacy of GPC on local fat dissolve and compared the effect with commonly used lipolytic agents (PPC and AMPL) using in vitro and in vivo models of obesity. In 3T3-L1 adipocytes, GPC inhibited fat accumulation during adipocyte differentiation while enhancing basal lipolysis in mature adipocytes (Fig. 2). The results from in vitro studies were in parallel with the reduction of adipocyte size and inguinal fat mass in GPC-injected mice (Fig. 4). These effects of GPC were more pronounced when compared to PPC and AMPL. The lipolytic effect of GPC was previously demonstrated in an experiment performed with obese-diabetic KK-A $\mathrm{A}^{\mathrm{y}}$ mice. Ten weeks of GPC administration in $\mathrm{KK}-\mathrm{A}^{\mathrm{y}}$ mice significantly reduced total cholesterol and triglyceride levels in serum [9]. These effects of GPC may be
A
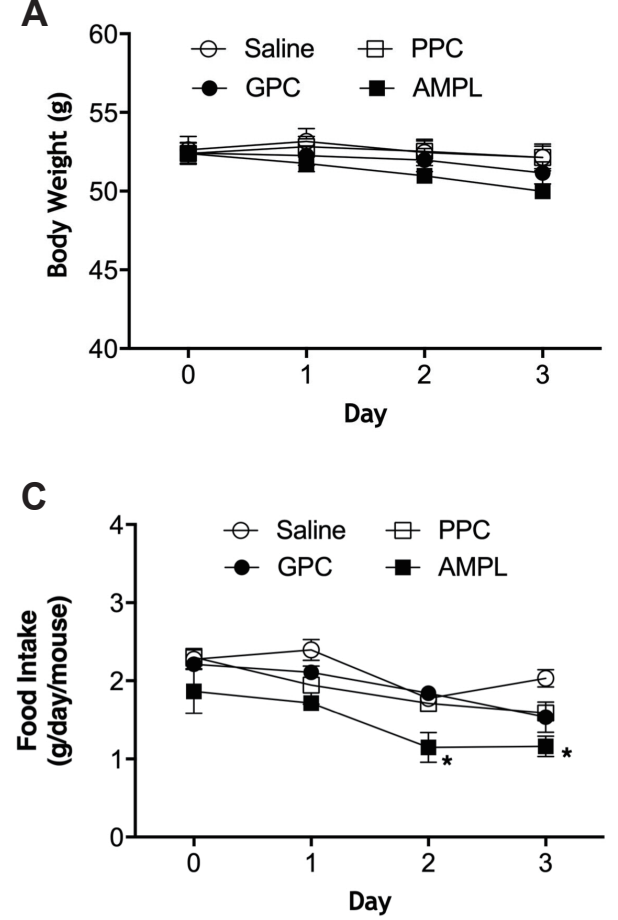

B
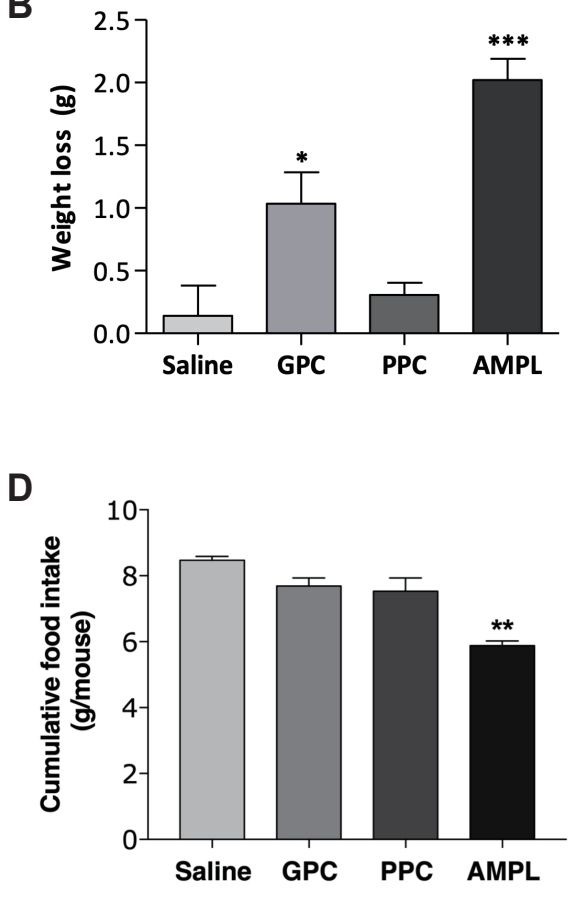

Fig. 3. Effect of GPC on body weight and food intake in DIO mice. (A) Change in body weight of the mice injected with GPC, PPC or AMPL was measured daily. Injection was initiated on day 0 and mice were sacrificed on day 3 . (B) Body weight loss after treatment was calculated. (C) Change in food intake of mice injected with GPC, PPC or AMPL was measured daily. (D) Cumulative food intake during injection period was calculated. GPC, glycerophosphocholine; PPC, phosphatidylcholine; AMPL, aminophylline; DIO, diet-induced obesity. ${ }^{*} p<0.05$, ${ }^{* *} p<0.01,{ }^{* * *} p<0.001$ vs. saline control. 

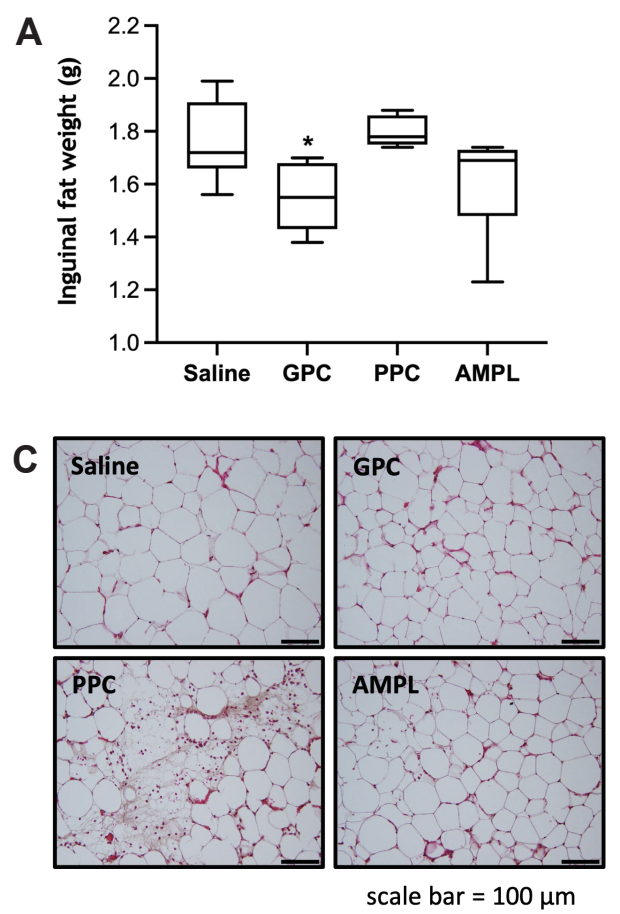
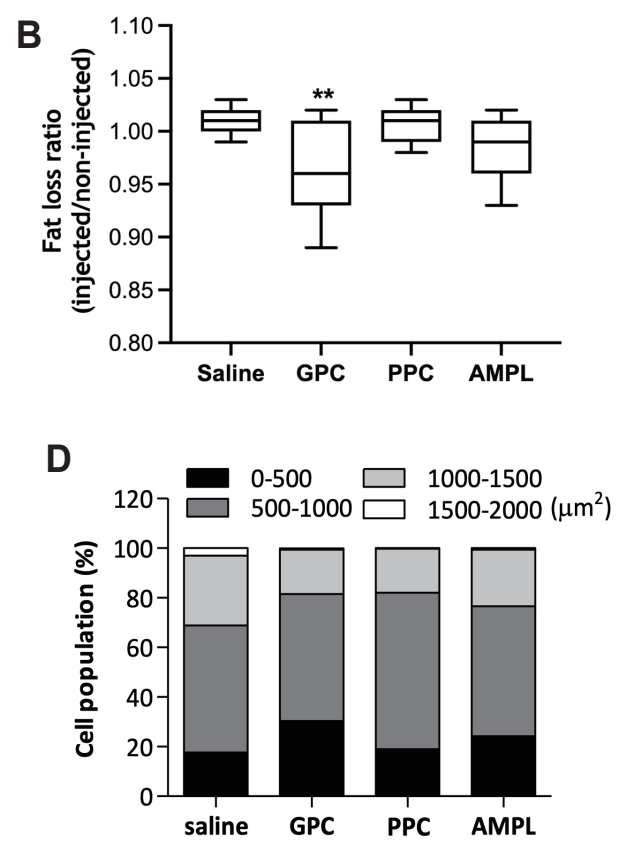

Fig. 4. Effect of GPC on localized fat reduction. (A) Inguinal adipose tissue was dissected and measured after 3 days of GPC, PPC or AMPL injection. * $p<0.05$ vs. saline control. (B) Ratio of injected or non-injected mouse inguinal fat pads mass was calculated. ${ }^{* *} p<0.01$ vs. saline control. (C) Inguinal adipose tissue section was prepared from injection site and stained by H\&E. Scale bars indicate $100 \mu \mathrm{m}$. (D) Adipocyte area was measured, and the distribution of adipocyte is shown in each size range. GPC, glycerophosphocholine; PPC, phosphatidycholine; AMPL, aminophylline. ascribed to choline-induced lipid metabolism. GPC is a useful source of choline, an essential nutrient required for cell membrane integrity and signaling and lipid transport $[10,11]$. This hypothesis can be supported by results reported by Kawamura et al. [12] that a single oral ingestion of $1,000 \mathrm{mg}$ GPC significantly elevated serum level of choline after $60 \mathrm{~min}$ of ingestion and subsequent increase in serum glycerol level after $120 \mathrm{~min}$ of ingestion in humans.

Lipolysis is the hydrolysis of triglyceride stored in intracellular lipid droplets for generation of energy in the form of fatty acids and glycerol. In adipose tissue, adipose triglyceride lipase (ATGL) is highly expressed and functions in hydrolyzing triglyceride and ATGL overexpression in 3T3-L1 adipocytes by adenovirusinfection resulted in an elevation of glycerol release [13]. ATGL is modulated by Ppar $\alpha$, a transcription factor that regulates fatty acid oxidation. Choline is reported to reduce hepatic triglyceride accumulation by upregulating Ppar $\alpha$, and genes involved in fatty acid oxidation [14]. The increase in mRNA expression level of Ppar $\alpha$ has been reported in the liver of GPC-fed mice suggesting that GPC may regulate lipid metabolism by activating downstream targets of Ppara such as ATGL [15].

One of the major findings of the present study is the histological changes in subcutaneous adipose tissue of mice injected with experimental solutions. In DIO mice, GPC and AMPL markedly reduced the size of adipocytes. However, PPC caused disrupted structure of adipocyte with noticeable signs of inflammation and tissue necrosis (Fig. 4C). Similarly, Noh and Heo [16] have reported significant inflammation, necrosis, and fibrosis in response to injection of PPC preparation in rat inguinal fat pad. Subcutaneous fat reduction by PPC injection has been suggested as a result of inflammation-mediated adipocyte apoptosis and resorption $[17,18]$. The results from histological analysis strongly support the different action mechanism of GPC and PPC on local fat dissolve, in which GPC reduces adipose tissue mass by stimulating lipolysis while PPC induces apoptosis in adipocytes. Moreover, PPC significantly inhibited 3T3-L1 adipocyte differentiation, however lipolytic activity was not observed in DIO mice injected with PPC (Fig. 2). Adipogenesis is a process of new fat cell formation and it can be regulated by apoptosis $[19,20]$. PPC has been reported to inhibit adipogenesis via inducing apoptosis in several studies [21,22], in parallel to our in vitro results showing decreased adipogenesis and in vivo results displaying adipose tissue necrosis by PPC (Fig. 4C). Surprisingly, we could not observe lipid reducing effect of PPC in mice (Fig. 4). This contradictory result could be explained by a previous study which reported that PPC injection reduced subcutaneous fat mass at day 7 post-injection but did not affect the tissue mass in a shorter period of injection [23]. It is worth noting that the lipolytic effect of AMPL was not significant when injected in inguinal fat pad in this study. Although AMPL is recognized as a stimulator of lipolysis, several studies reported that AMPL injection is not effective in reducing local fat $[24,25]$. The body weight loss and decrease in adipocyte size by AMPL are likely to be attributed to significant decrease in food intake.

In summary, we found that GPC inhibited adipogenesis and enhanced basal lipolysis, leading to a reduction of adipocyte size and subsequent loss of local fat. GPC also exhibited relatively low cytotoxicity. Together, these observations support the potential use of GPC as an injection lipolytic agent. However, further studies are needed to investigate the molecular mechanism of GPC in reducing local fat and the safety of using GPC for the purpose of 
injection lipolysis.

\section{ACKNOWLEDGEMENTS}

We thank to Beauvous Co. for providing Alfocholine Inj., Lipobean i.v., Aminophylline Injection Huons and valuable information related to this study.

\section{CONFLICTS OF INTEREST}

The authors declare no conflicts of interest.

\section{REFERENCES}

1. Couillard C, Gagnon J, Bergeron J, Leon AS, Rao DC, Skinner JS, Wilmore JH, Després JP, Bouchard C. Contribution of body fatness and adipose tissue distribution to the age variation in plasma steroid hormone concentrations in men: the HERITAGE Family Study. J Clin Endocrinol Metab. 2000;85:1026-1031.

2. O'Brien KS, Latner JD, Ebneter D, Hunter JA. Obesity discrimination: the role of physical appearance, personal ideology, and anti-fat prejudice. Int J Obes (Lond). 2013;37:455-460.

3. Alizadeh Z, Halabchi F, Mazaheri R, Abolhasani M, Tabesh M. Review of the mechanisms and effects of noninvasive body contouring devices on cellulite and subcutaneous fat. Int J Endocrinol Metab. 2016;14:e36727.

4. Hasengschwandtner F. Injection lipolysis for effective reduction of localized fat in place of minor surgical lipoplasty. Aesthet Surg J. 2006;26:125-130.

5. Zeisel SH. Choline: critical role during fetal development and dietary requirements in adults. Annu Rev Nutr. 2006;26:229-250.

6. Nair AB, Jacob S. A simple practice guide for dose conversion between animals and human. J Basic Clin Pharm. 2016;7:27-31.

7. Jung GS. Effectiveness of local fat-dissolving solution injection. Aesthet Surg J. 2019;39:NP156-NP158.

8. Galarraga M, Campión J, Muñoz-Barrutia A, Boqué N, Moreno H, Martínez JA, Milagro F, Ortiz-de-Solórzano C. Adiposoft: automated software for the analysis of white adipose tissue cellularity in histological sections. J Lipid Res. 2012;53:2791-2796.

9. Izu H, Okuda M, Shibata S, Fujii T, Matsubara K. Anti-diabetic effect of S-adenosylmethionine and a-glycerophosphocholine in KKAy mice. Biosci Biotechnol Biochem. 2019;83:747-750.

10. Zeisel SH, Blusztajn JK. Choline and human nutrition. Annu Rev Nutr. 1994;14:269-296.

11. Biswas S, Giri S. Importance of choline as essential nutrient and its role in prevention of various toxicities. Prague Med Rep. 2015;116:515.

12. Kawamura T, Okubo T, Sato K, Fujita S, Goto K, Hamaoka T, Iemitsu M. Glycerophosphocholine enhances growth hormone secretion and fat oxidation in young adults. Nutrition. 2012;28:1122-1126.

13. Zimmermann R, Strauss JG, Haemmerle G, Schoiswohl G, BirnerGruenberger R, Riederer M, Lass A, Neuberger G, Eisenhaber F, Hermetter A, Zechner R. Fat mobilization in adipose tissue is promoted by adipose triglyceride lipase. Science. 2004;306:1383-1386.

14. Zhu J, Wu Y, Tang Q, Leng Y, Cai W. The effects of choline on hepatic lipid metabolism, mitochondrial function and antioxidative status in human hepatic C3A cells exposed to excessive energy substrates. Nutrients. 2014;6:2552-2571.

15. Narukawa M, Kamiyoshihara A, Izu H, Fujii T, Matsubara K, Misaka T. Efficacy of long-term feeding of a-Glycerophosphocholine for aging-related phenomena in old mice. Gerontology. 2020;66:275285.

16. Noh Y, Heo CY. The effect of phosphatidylcholine and deoxycholate compound injections to the localized adipose tissue: an experimental study with a murine model. Arch Plast Surg. 2012;39:452-456.

17. Rose PT, Morgan M. Histological changes associated with mesotherapy for fat dissolution. J Cosmet Laser Ther. 2005;7:17-19.

18. Schuller-Petrovic S, Wölkart G, Höfler G, Neuhold N, Freisinger F, Brunner F. Tissue-toxic effects of phosphatidylcholine/deoxycholate after subcutaneous injection for fat dissolution in rats and a human volunteer. Dermatol Surg. 2008;34:529-542; discussion 542-543.

19. Ristow M, Müller-Wieland D, Pfeiffer A, Krone W, Kahn CR. Obesity associated with a mutation in a genetic regulator of adipocyte differentiation. N Engl J Med. 1998;339:953-959.

20. Sorisky A, Magun R, Gagnon AM. Adipose cell apoptosis: death in the energy depot. Int J Obes Relat Metab Disord. 2000;24 Suppl 4:S3-S7.

21. Jung TW, Park T, Park J, Kim U, Je HD, Kim HD, Cho SW, Abd ElAty AM, Song JH, Kim HC, Shin YK, Jeong JH. Phosphatidylcholine causes adipocyte-specific lipolysis and apoptosis in adipose and muscle tissues. PLoS One. 2019;14:e0214760.

22. Li H, Lee JH, Kim SY, Yun HY, Baek KJ, Kwon NS, Yoon Y, Jeong JH, Kim DS. Phosphatidylcholine induces apoptosis of 3T3-L1 adipocytes. J Biomed Sci. 2011;18:91.

23. Won TJ, Nam Y, Lee HS, Chung S, Lee JH, Chung YH, Park ES, Hwang KW, Jeong JH. Injection of phosphatidylcholine and deoxycholic acid regulates gene expression of lipolysis-related factors, proinflammatory cytokines, and hormones on mouse fat tissue. Food Chem Toxicol. 2013;60:263-268.

24. Kim HK, Kim YW, Kim HJ. The evaluation of the effect of aminophylline injection to subcutaneous fat reduction. J Korean Soc Aesthet Plast Surg. 2003;9:17-21.

25. Park SH, Kim DW, Lee MA, Yoo SC, Rhee SC, Koo SH, Seol GH, Cho EY. Effectiveness of mesotherapy on body contouring. Plast Reconstr Surg. 2008;121:179e-185e. 